\title{
Los soportes textiles de las pinturas mexicanas: estudio estadístico e histórico
}

\author{
Rita Sumano González
}

Introducción

a pintura de caballete, que recibe su nombre del armazón trípode que se utiliza para sostener el bastidor o la tabla sobre los que se ha de pintar, ha - sido una de las expresiones artísticas más socorridas en México desde la conquista española. Sus características formales se han modificado a lo largo del tiempo tanto como su materialidad y técnica de factura; sin embargo, aun hasta hace poco, se ha estudiado la imagen en menoscabo de la materialidad del objeto, provocando un desequilibrio en el conocimiento que tenemos sobre las obras. Por tal razón, esta investigación decidió enfocarse en la técnica de factura de los soportes textiles de la pintura de caballete en el México de los siglos XVII al XIX, para así ayudar a entender e interpretar la evidencia material que contienen las pinturas.

En el ámbito de la restauración, a la base o sustento sobre la que se realiza una pintura se le llama soporte, donde el textil es la forma más frecuente de sustentarla. Si bien los soportes textiles suelen presentar estructuras particulares que los caracterizan según las distintas épocas y escuelas artísticas, no existen, sin embargo, estudios detallados a este respecto y los tratados de pintura no abundan en las descripciones sobre los lienzos. En el año 2005 se llevó a cabo el congreso Interim Meeting: International Conference on Painting Conservation. Canvases: Behavior, Deterioration \& Treatment, donde varios ponentes discutieron el tema de los soportes textiles, centrándose principalmente en los procesos de restauración que los afectan. Hasta el momento, Konrad Laudenbacher es el único autor que menciona la importancia de indagar en los soportes textiles como parte de la evidencia material que nos deja la pintura, señalando la necesidad de hacer estudios exhaustivos a este respecto (Laudenbacher 2005:111-118).

El estado del soporte es fundamental para la conservación de las pinturas y muchas veces las alteraciones que aparecen en la superficie son efectos provenientes de problemas en él. Los procesos de restauración inciden directamente no sólo sobre la imagen, sino también sobre la materialidad del objeto, pudiendo modificar sus características de manera irreversible. Al entender la importancia de la evidencia contenida en los soportes textiles de las pinturas de caballete, se comprenden los alcances de una intervención de restauración que modifique las características originales de la obra. Un análisis y registro adecuado del reverso de las obras ayudará a proteger la valiosa evidencia que contienen los soportes $-\mathrm{y}$ los bastidores—; a su vez, mejorará la caracteri- 
zación del deterioro presente y, por tanto, ayudará a establecer pautas para llevar a cabo métodos de limpieza, refuerzos y montajes adecuados.

Los soportes textiles de las pinturas de caballete tienen dos momentos de creación igualmente importantes: aquel en el que fueron facturados como lienzos y en el que estos mismos lienzos fueron usados como soportes de pinturas. Este artículo se basa en un estudio que he elaborado como parte de la tesis de licenciatura titulada Estudio de la técnica de factura de los soportes textiles de la pintura de caballete en México, siglos XVII al XIx (Sumano 2010). En esta ocasión abordaré solamente la parte relativa a la técnica de factura de los soportes textiles de las pinturas, mientras que en publicaciones posteriores será necesario tratar la forma en que dichos lienzos fueron usados como soportes, así como ahondar en la metodología de registro y estudio estadístico.

El estudio está basado en los informes de trabajo elaborados por los estudiantes de la Licenciatura en Restauración que cursaron el Seminario-Taller de Restauración de Pintura de Caballete de la Escuela Nacional de Conservación, Restauración y Museografía del Instituto Nacional de Antropología e Historia (STRPC-ENCRYM-INAH) entre los años 1997 y 2009. De dichos informes se extrajo un número total de cuadros de acuerdo con los siguientes criterios de inclusión de muestra: que las pinturas hubieran sido intervenidas y registradas en el STRPC; que tuvieran soporte textil; que se tratara de pintura producida en territorio mexicano; que pertenecieran a los siglos XVII, XVIII O XIX; que no existieran dudas respecto del siglo en el que fueron pintadas; que las intervenciones anteriores al momento del informe no hubieran modificado irreversiblemente los datos del soporte; que el informe donde se encontraron registrados los datos sea confiable y esté respaldado por pruebas científicas (observación bajo microscopio, pruebas a la gota, análisis materiales e instrumentales, etcétera).

Para sistematizar la información, se realizó una base de datos electrónica y se cuantificó la incidencia de las características de los soportes textiles según variables establecidas en una ficha de análisis textil basada en los trabajos de Irmgard Johnson, que abordan al textil desde su materia prima hasta el hilado, y desde la conformación del tejido hasta su posible uso y contexto socioeconómico (Johnson 1977: anexo). Las variables relativas a la técnica de factura de los lienzos se abordaron desde la materia prima hasta la conformación del hilado y del tejido.

Con las variables establecidas, se realizó estadística cuantitativa y descriptiva (porcentajes, media, mediana, rangos, desviación estándar, y correlaciones) con la ayuda del programa Excel ${ }^{\circledR}$ y OriginPro 8 SR0 ${ }^{\circledR}$. De los 352 informes revisados originalmente, 152 se excluyeron por no cumplir con los criterios de inclusión de muestra, y los 200 cuadros restantes constituyeron el tamaño de muestra o "N". En total, se examinaron 27 registros del siglo xVII, 136 del XVIII y 37 del XIX. Los resultados de este análisis estadístico ayudaron a orientar la investigación histórica, que se sirvió de fuentes vivas, materiales, bibliográficas y documentales.

\section{Antecedentes históricos de la actividad textil en México}

El desarrollo de la actividad textil en México durante los siglos en cuestión se puede explicar a partir de la rica herencia prehispánica y de la forma en que se incorporaron las nuevas tecnologías provenientes del Viejo Mundo. Está bien documentada una gran cantidad de técnicas prehispánicas aplicadas a textiles novohispanos, como casullas y paños de altar, lo cual demuestra que la comunidad indígena siguió involucrada en la producción textil colonial, desde el cultivo de la fibra, hasta la conformación del hilo, el tejido y el teñido.

A principios de la vida colonial, la implantación de especies nuevas en territorio americano dio como fruto excelentes cosechas de vid, seda, algodón, lino, cáñamo, olivo y otros cultivos; sin embargo, esto duraría poco, ya que para proteger el mercado peninsular, en 1596 el virrey conde de Monterrey recibiría la orden de prohibir la resiembra de estos productos en las colonias.

En 1524 se reglamentaron varios oficios a través de ordenanzas, entre ellos el de los obrajeros, quienes trabajaban principalmente con lana y algodón. En 1545 Carlos $\vee$ pidió a los gobernadores de Indias que fomentaran entre los criollos las manufacturas textiles de seda, algodón, lino y cáñamo, por lo que fue necesario rehacer las ordenanzas e incluir en ellas otros oficios que se ocupaban de diferentes fibras textiles. Fue así como el 4 de agosto de 1550 se dictaron las Ordenanzas de cordoneros y xaquimas. ${ }^{1}$ Éstas regularían la producción de estopas, sogas y jáquimas de cáñamo, henequén, algodón y lana, con determinación precisa de su grosor, el número de cabos que debían tener las jarcias y cómo debían hacerse. Posteriores ordenanzas, expedidas por el virrey Luis de Velasco en 1592, estuvieron dirigidas a "pañeros, como obrajeros y otro cualesquiera que hiciere sayales", ${ }^{2}$ y fue sólo hasta 1721 cuando se dictaron las Otras ordenanzas de sayaleros, específicas para ellos, puesto que en un inicio este oficio estaba considerado como parte de los obrajeros $^{3}$ (Barrio Lorenzot 1932:62). Los intentos tardíos

\footnotetext{
1 Jáquima: cabezada de cordel que hace las veces de cabestro (Casares 1994:488).

2 Hoy en día, la palabra sayal define a una tela muy basta de lana (Casares 1994:758), sin embargo, es necesario aclarar que en las ordenanzas no hay palabra alguna sobre el material constitutivo de los sayales.

${ }^{3}$ Los obrajes surgieron como productores de telas de lana, por lo que no son directamente relevantes para esta investigación, salvo en la medida en que acogieron su sistema corporativo a otros sectores de la producción textil. El "obraje de paños" en la Nueva España se refería a la producción textil en todos sus pasos, desde el lavado y cardado, hasta el tejido y teñido, todos bajo un mismo techo. Confróntese con Miño Grijalva (1993) y Viqueira y Urbiola (1990).
} 
por regular la profesión pueden indicar la repentina necesidad de normalizar un mercado que no se había pautado cabalmente, por carecer hasta entonces de relevancia para la economía novohispana o por guarecerse parcialmente en el tráfico de manufacturas extranjeras dentro del territorio mexicano.

Hacia finales del siglo xvIII, una parte de la población vivía de la producción subyacente o domiciliaria, ajena a la organización gremial; tal es el caso de los establecimientos privados dedicados al hilado y la costura de prendas femeninas. Éstos, a pesar de la oposición del gremio, habían fructificado en la Ciudad de México debido a que su necesidad y costo en materiales era menor a la de otros oficios (González Angulo 1983:235). En sectores rurales había talleres o trapiches orientados al autoconsumo, paralelamente y en coexistencia con los obrajes. Por esto, es posible suponer que parte importante de los lienzos usados en las pinturas de caballete novohispanas fue producida en territorio americano, desde el cultivo de las fibras, hasta su hilado y tejido. Su factura se habría hecho en un contexto rural, de acuerdo con la accesibilidad a cultivos cercanos, en talleres y trapiches operados por indígenas o castas. Esto se puede corroborar en las diferencias de calidad de los soportes de las pinturas, condición que permanecería durante todo el siglo xIx.

Las adversas condiciones sociopolíticas que vivió el país tras su independencia sumergirían a la industria textil mexicana en un terrible aprieto. El Banco de Avío quiso fomentar la industria nacional comprando maquinaria nueva y motorizada, proveyendo a los productores con mejores variedades de gusano de seda, lino y cáñamo, así como tratando de impulsar la inversión extranjera. No obstante, las constantes guerras y la falta de capital mermarían significativamente la producción textil. Los principales consumidores de textiles europeos eran los estratos alto y medio alto de la Ciudad de México, mientras que el resto de los habitantes siguió usando los productos de los fabricantes locales, y las poblaciones indígenas, portando sus trajes tradicionales.

Hacia la segunda mitad del siglo xIx, algunos establecimientos actualizaron la maquinaria que habían adquirido a principios de ése, e incorporaron todos los procesos de producción de la fábrica, aunque tardarían muchos años en modernizarse por completo, y en la mayoría de los casos convivieron procesos manuales e industriales bajo un mismo techo.

\section{Los materiales constitutivos de los lienzos}

La estructura del soporte determina en forma esencial la superficie de la pintura: cambia su brillo, color y textura. La fibra constitutiva de un textil origina muchas de sus características finales, pues las características microscópicas de las fibras se reflejan en el resultado macroscópico del lienzo. Un soporte de algodón, por ejemplo, por las convolusiones ${ }^{4}$ que presenta la fibra en su corte longitudinal, resulta difícil de tensar sobre un bastidor pues se deforma y contrae al contacto con el agua. Por el contrario, el lino es una fibra resistente que soporta las tensiones del montaje, mantiene sus dimensiones originales y no se deforma con facilidad. Formal o instintivamente, los pintores saben que la calidad y características de los lienzos influirán tarde o temprano en el estado de conservación de la pintura, por lo que la elección de un soporte textil adecuado resulta un asunto crucial durante el proceso de creación.

Noventa por ciento de los informes que formaron parte de la base de datos analizada registra los materiales constitutivos de los lienzos, ${ }^{5}$ lo que nos mostró que durante el siglo XVII todos los lienzos usados en estas pinturas estaban hechos de lino, tanto a la trama como a la urdimbre. De los siguientes cien años, solamente dos cuadros presentan variación: uno con soporte de yute, y otro de lino y yute: Virgen de Guadalupe, procedente de San Miguel Acambay, Hidalgo, y San Andrés, Dolorosa y San Jorge, de Jonacatepec, Morelos.

Por lo ya mencionado, desde la prohibición de 1596, de la resiembra de varios productos agrícolas, los lienzos de lino debían provenir de España o de países industrializados. Sin embargo, para finales del siglo xVIII en España la población se había duplicado y la demanda de este material había aumentado notablemente. Esto se vio acentuado a causa de la abierta pugna entre España e Inglaterra por el dominio del océano Atlántico, lo que incrementaba mayormente la demanda de lienzos, jarcias y cordajes de lino y cáñamo. Por ello, se volvió a considerar las tierras americanas como una gran promesa: en ellas se cultivaría la materia prima, para luego procesarla en la Península, y el producto terminado se vendería de nuevo en América. A decir de Ramón Serrera, la incapacidad de la producción española para atender su propia demanda, y la política proteccionista y colonial vigente en la Península, fueron las razones principales por las cuales se intentó reiniciar el cultivo de lino en la Nueva España hacia finales del siglo XVIII, a pesar de que los estudios ya habían demostrado la inutilidad del proyecto desde antes de su implantación (Serrera 1974:91-93).

La producción de lino en la Nueva España no resultaría suficiente para satisfacer la demanda. Su fabricación y traslado resultaban tres veces más caros que importar lienzos de Holanda o Suecia, por lo que el proyecto fue abandonado al poco tiempo. Sin embargo, es muy probable que las cosechas de lino implantadas a finales del XVIII continuaran existiendo en reducidas localidades mexicanas, y que hayan sido éstas las que abastecieron parcialmente el mercado interno durante el siglo xIX.

\footnotetext{
${ }^{4}$ Giros o torsiones en la sección longitudinal de la fibra de algodón, característica que le confiere elasticidad y absorbencia.

${ }^{5}$ En todos los casos, la caracterización se hizo a partir de la observación de cortes longitudinales bajo el microscopio óptico.
} 
Dado el aumento de demanda de materia prima durante el siglo XIX, y la escasez producida en México por los factores sociopolíticos antes mencionados, la producción de pintura tuvo que adaptarse a los lienzos disponibles, pero mantuvo la preferencia por aquellos hechos de lino en $69.44 \%$ de los casos analizados. El resto fue hecho a partir de otras fibras: $16.67 \%$ de algodón, $2.78 \%$ de cáñamo y $11.12 \%$ de lino en combinación con cáñamo, yute y/o algodón (Figuras 1 y 2).

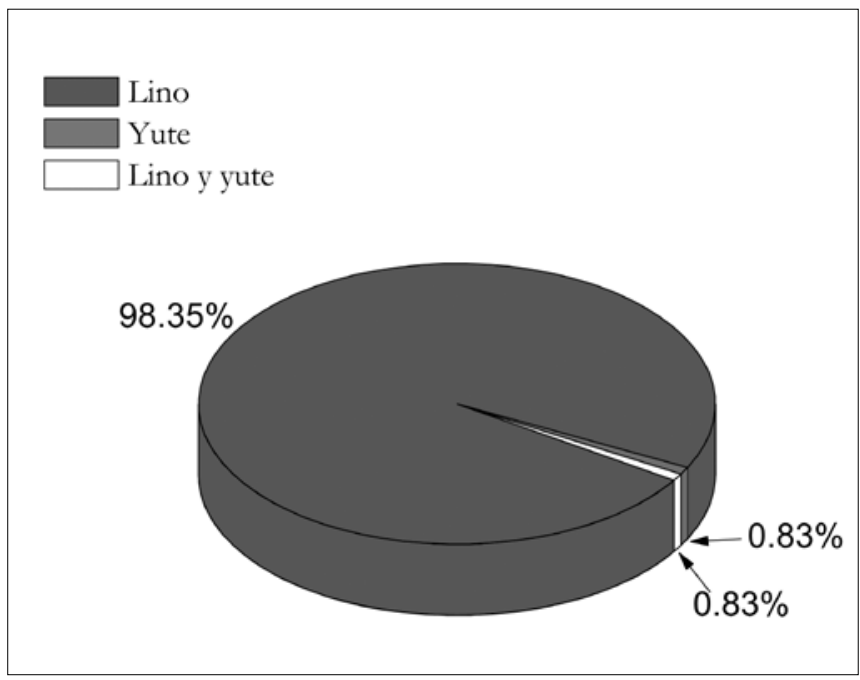

FIGURA 1. Identificación de fibra textil utilizada en la trama y urdimbre del tejido de los lienzos del siglo xvIII.

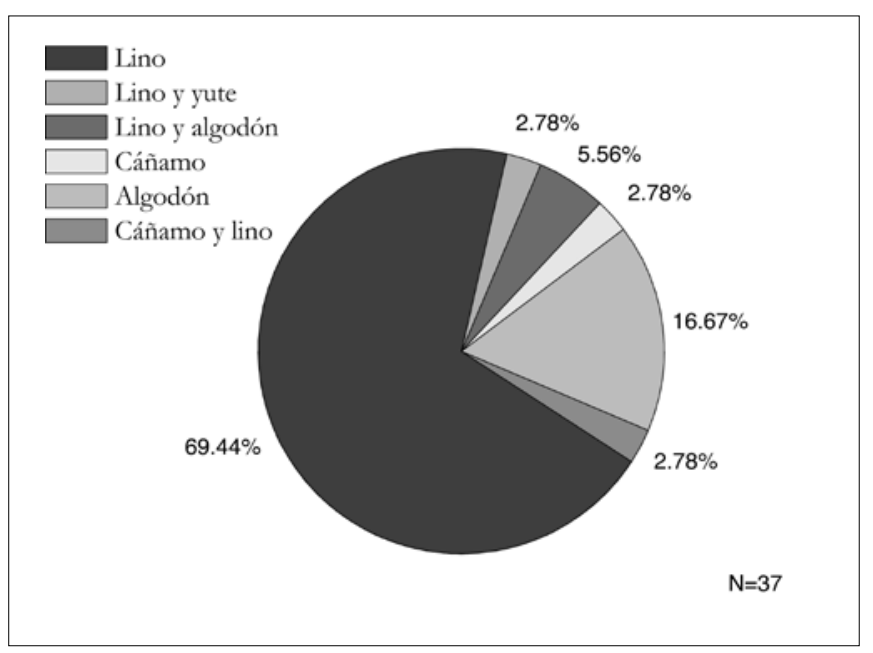

FIGURA 2. Identificación de fibra textil utilizada en la urdimbre del tejido de los lienzos del siglo xIX.

\section{Las costuras de unión}

Un lienzo puede ser tan largo como se desee, pero su anchura está limitada por las dimensiones del telar, por lo que en ocasiones fue necesario usar más de un lienzo para conformar soportes extensos. Para unir los lienzos se usaron hilos de diferentes fibras: en el siglo xvII se presentan fibras de agave $(12.5 \%$ de nuestra muestra) y de seda (12.5\%); en el resto de los casos no hay registros. Para cuadros del siglo XVIII encontramos que $6.5 \%$ son de fibras de yute, $1.61 \%$ de algodón con seda, 3.23\% de agave y $4.84 \%$ de lino. El resto de los informes no lo especifica.

En Otras ordenanzas de sayaleros (1721) se documenta la existencia de una producción textil indígena que, como ya hemos visto, se manejaba en forma independiente de los obrajes y los gremios, y ésta se puede corroborar en las pinturas por la presencia de hilos de costura o unión hechos con fibras de plantas cultivadas desde el México precolombino como el agave y el algodón. De conformidad con lo pedido por el señor procurador mayor, se dice que

Quedaban libres y exceptuados de estas ordenanzas los indios para no embarazarles el que libremente puedan hacer sus tejidos como lo han hecho hasta aquí los de Texcoco, u otros países, sin cuentas, ni reglas, por la comodidad de los precios a que los venden y no impedirles su modo de buscar mantenimiento, y paga de los reales tributos (Barrio Lorenzot 1932:74).

La industria sericícola se implantó en la Nueva España temprana y exitosamente, pero su cultivo también fue prohibido en 1596. Esto provocó que muchos de los cultivadores de seda se inclinaran por el algodón o incluso mezclaran ambas fibras, como se puede constatar en $1.61 \%$ de las costuras de unión de los lienzos del siglo XVIII analizados, donde en un mismo hilo se mezcla seda y algodón.

El material constitutivo de costuras de unión de los cuadros restaurados que corresponden al siglo XIX no pudo caracterizarse debido a que $83.78 \%$ de los lienzos de las pinturas decimonónicas analizadas constan de un solo miembro, y el resto carece de registro.

\section{Hilado}

El hilado de fibras textiles puede hacerse tanto manual como mecánicamente. Puesto que se requiere gran habilidad para obtener hilos elaborados a mano que sean relativamente regulares, un hilado manual se caracteriza por dar como resultado hilos con un diámetro variable, que suelen provocar nudos y torsiones diferenciales. Un hilado auxiliado por medios mecánicos resulta en un hilo con torsión y diámetro regular, que genera tejidos más homogéneos y con mucho menos nudos.

En cuadros de los siglos estudiados es posible observar que hay tanto hilados manuales como mecánicos. De nuestra muestra, $51.85 \%$ de los lienzos del siglo xvII registran hilado manual, mientras que $44.12 \%$ del xVIII presentan esta misma técnica de elaboración. Sólo $7.41 \%$ y $5.15 \%$ de los lienzos estudiados, de los siglos XVII y XVIII, respectivamente, presentan un hilado mecánico (Figuras 3 y 4$)$.

De los lienzos de las pinturas de caballete del siglo xIx, $29.73 \%$ fueron hilados manualmente y $27.03 \%$ mecáni- 


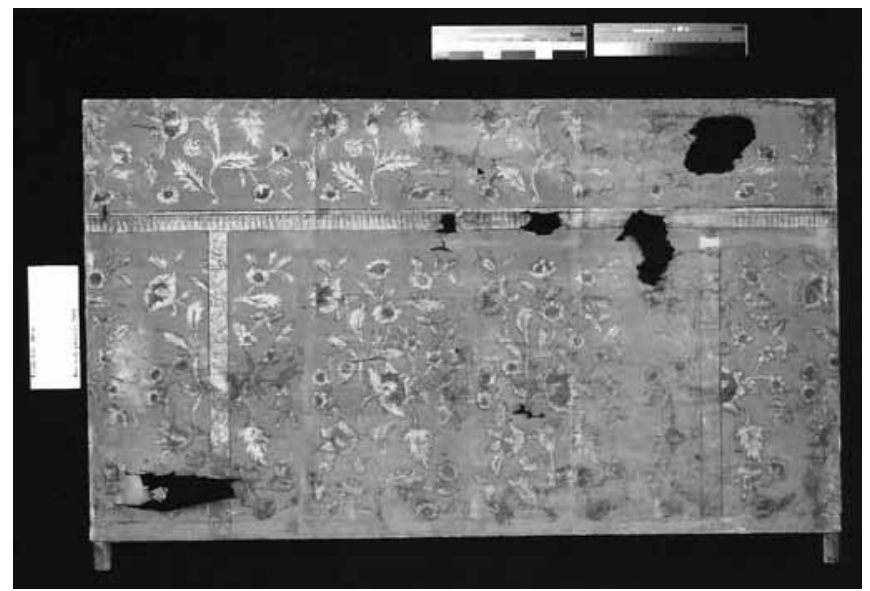

FIGURA 3. Frontal de Altar, siglo xVIII, Capilla de Santa Lucía, Jonacatepec, Morelos. (Tomado de Alcántara 2008; cortesía: Archivo del STRPC-ENCRYM).

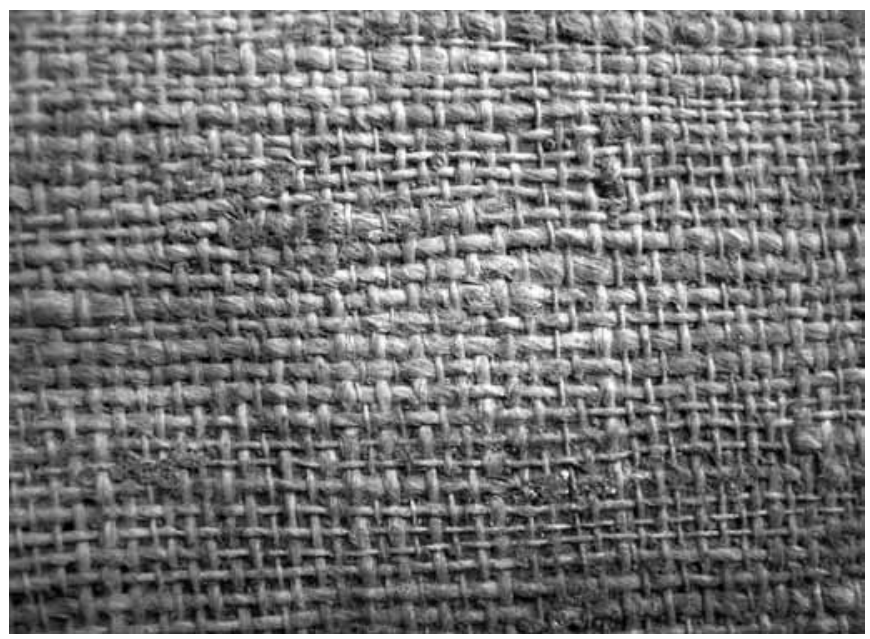

FIGURA 4. Detalle del soporte de la obra Frontal de Altar, siglo XVIII, con hilado manual y densidad de tejido baja. (Tomado de Alcántara 2008; cortesía: Archivo del STRPC-ENCRYM).

camente, lo que significa que el hilado manual disminuye sólo $10 \%$ respecto del siglo anterior. Es necesario destacar que $82 \%$ de los lienzos examinados del siglo xix que presentan hilado manual estaban hechos de lino, y sólo $18 \%$, de algodón. Lo anterior se explica, pues las novedosas máquinas decimonónicas que llegaron a México estaban diseñadas para trabajar algodón y lana, por lo que el lino debió seguirse hilando manualmente. En contraste, es posible inferir que aquellos lienzos de lino con hilado mecánico pudieron provenir de países industrializados y exportadores, como Holanda e Inglaterra, donde sí se contaba con la tecnología para procesar esta fibra.

\section{Densidad de tejido}

La densidad de tejido se refiere a la cantidad de hilos por centímetro cuadrado que hay en una tela. Esta característica determina su caída, peso, capilaridad y capacidad absorbente; también nos habla de la forma de factura de la tela, pues, generalmente, a mayor densidad de hilos, mayor es el grado de industrialización.

La densidad se reporta en hilos $/ \mathrm{cm}^{2}$, pero, para hacer una estadística descriptiva con/sobre esta variable, se hizo una suma de los hilos en los sentidos de la trama y la urdimbre, con el fin de utilizarla como valor de densidad de tejido absoluta, representada en las figuras 3 y 4 . Se observó que la media ${ }^{6}$ de densidad de tejido no varía significativamente del siglo XVII al XVIII, y equivale a 11 X 12 o $12 \times 13$ hilos $/ \mathrm{cm}^{2}$. En contraste, en el siglo siguiente la media aumenta hasta $16 \times 17$ o $15 \times 18$ hilos/cm². Para cuadros del siglo XVII, el rango se mantiene entre los $14 \mathrm{y}$ los 38 hilos; en el XVIII éste aumenta de 11 a 58 y en el XIX se reduce de 13 a 53 hilos. Esto sugiere que los lienzos usados durante los siglos XVII y XVIII fueron muy similares, marcando una continuidad en la tradición colonial.

En las Ordenanzas de sayales y sayaleros de 1592 podemos encontrar una referencia precisa a la densidad de tejido de las telas, cuando se pide que se hagan de una baza y cuarta de ancho, con veinte guiñuelos de a veinte y cuatro hilos cada guiñuelo, ${ }^{7}$ so pena de diez pesos [...] y perdidos los sayales por la primera vez, y por la segunda perdidos los sayales, y la pena doble, y privación de oficio por tres años (Barrio Lorenzot 1932:62).

Las Otras ordenanzas de sayaleros, de 1721, son increíblemente puntuales sobre el número de hilos y varas que debía medir cada pieza, dependiendo de su uso. En ellas, se hace una clara distinción entre los tipos de textiles: jerga, sayal, petatillo, frezada y sayalillo, y más aún entre el tipo de textil que se ha de usar para cada santo patrono y para cada orden religiosa en la Nueva España, con especificación de color, dimensiones y densidad de tejido. Sin embargo, nada se dice sobre las telas que se habrían de usar como soportes de pinturas.

Por otro lado, en nuestro análisis la desviación estándar ${ }^{8}$ de la densidad de tejido aumenta conforme se acerca al siglo xIX, lo que significa que el contraste en la densidad de tejido es mucho mayor que en las centurias anteriores. Este dato nos permite corroborar la existencia de dos tipos de lienzos utilizados en el siglo xIx: aquellos

\footnotetext{
${ }^{6}$ En estadística descriptiva, la media corresponde a la suma de todos los datos dividida por el número total de ellos. Es lo que se conoce como "promedio".

${ }^{7}$ Se ha intentado ubicar infructuosamente, en diferentes tipos de diccionarios, las acepciones de las palabras baza y guiñuelo en relación con el tema que aquí se trata. Según la explicación de la autora de El encaje de Hinojosa. Historia y técnica, el primer término probablemente sea braza (unidad de medida usada para las telas del doble de la vara; ésta, de $80 \mathrm{~cm}$ ) y no baza; el segundo significa en leonés, madeja (Mariña Regueiro, comunicación electrónica, 18 de marzo de 2011).

8 Desviación estándar es un estadígrafo que representa la variabilidad existente en un conjunto de datos, ya que por ejemplo dos grupos de cifras pueden presentar la misma media aritmética, pero poseer distinta variabilidad, por eso nos permite entender el grado de variabilidad o dispersión de los datos.
} 
producidos en contextos domésticos, con densidades de tejido bajas y aquellos importados de países industrializados, que cuentan con densidades de tejido medias y altas. Esta misma tendencia se mantiene al cotejar las densidades de tejido presentes sólo en los lienzos hechos de lino (Figuras 9 y 10).

\begin{tabular}{|c|c|c|c|c|c|c|}
\hline Siglo & $\begin{array}{c}\text { (Número } \\
\text { total de } \\
\text { lienzos) }\end{array}$ & Media & $\begin{array}{c}\text { Desviación } \\
\text { estándar }\end{array}$ & Mediana & \multicolumn{2}{|c|}{ Rango } \\
\hline & 35 & 22.82 & 4.67 & 22 & 14 & 38 \\
\hline XVII & 35 & 23.92 & 7.69 & 22 & 11 & 58 \\
\hline XVIII & 193 & Mínimo & Máximo \\
\hline XIX & 46 & 33.32 & 10.47 & 32 & 13 & 53 \\
\hline
\end{tabular}

FIGURA 5. Tabla sumaria de estadística descriptiva de la variable densidad de tejido absoluta, siglos XVII, XVIII y xIx. Nota: en estadística descriptiva se denomina rango estadístico $(R)$ al intervalo de menor tamaño que contiene a los datos. Permite obtener una idea de la dispersión de los mismos. La mediana es aquel valor que ocupa el lugar central, de modo que la mitad de los casos queda por debajo de ese valor y la otra mitad por encima.

\begin{tabular}{|c|c|c|c|c|c|c|}
\hline Siglo & $\begin{array}{c}\text { (Número } \\
\text { total de } \\
\text { lienzos) }\end{array}$ & Media & $\begin{array}{c}\text { Desviación } \\
\text { estándar }\end{array}$ & Mediana & \multicolumn{2}{|c|}{ Rango } \\
\hline XIX & 25 & 30.62 & 9.59 & 30 & 13 & 49 \\
\hline
\end{tabular}

FIGURA 6. Tabla sumaria de estadística descriptiva de la variable densidad de tejido de los lienzos de lino del siglo xIX.

Es posible observar, asimismo, que aquellos lienzos con densidades de tejido altas fueron utilizados por pintores de la élite, que por lo general retrataban y estaban ligados a la burguesía de aquella época, mientras que sólo un cuadro con baja densidad de tejido (San Roque, proveniente del Museo Regional de Tlaxcala) iba firmado por su autor: Juan José Yllanes. Las figuras 7, 8, 9 y 10 ilustran ejemplos de lienzos de distintos tipos de factura: $\mathrm{La} \mathrm{Co}^{-}$ ronación de la Virgen, con un soporte de densidad baja, y otro de factura industrializada, seguramente importado, que retrata a un personaje notable del siglo xix: el general Trinidad García de la Cadena.

Sólo $2.78 \%, 6.17 \%$ y $2.13 \%$ de los cuadros analizados de los siglos XVII, XVIII y XIX, respectivamente, carecen del registro de la densidad de tejido.

\section{Ligamento textil}

Durante los siglos XVII y xVIII el ligamento textil del que estuvieron hechos todos los soportes fue el tafetán, donde cada hilo de urdimbre se entrelaza con cada uno de los hilos de trama. En los cuadros analizados del siglo XIX el ligamento simple permanece, con la salvedad de dos cuadros con ligamento en sarga (donde los hilos de urdimbre y trama hacen bastas por encima de dos o más hilos de la dirección opuesta, marcando una progresión regular). Esta preponderancia se explica por ser el tafetán el ligamento textil más sencillo y accesible, por proveer al cuadro con una regularidad visual y soportar de manera uniforme las tensiones provocadas por la unión del lienzo al bastidor. La introducción del ligamento en sarga en algunos lienzos evidencia el acceso a textiles de factura industrializada, puesto que, por su estructura, la sarga resulta un ligamento difícil de elaborar en telares manuales y de pedales.

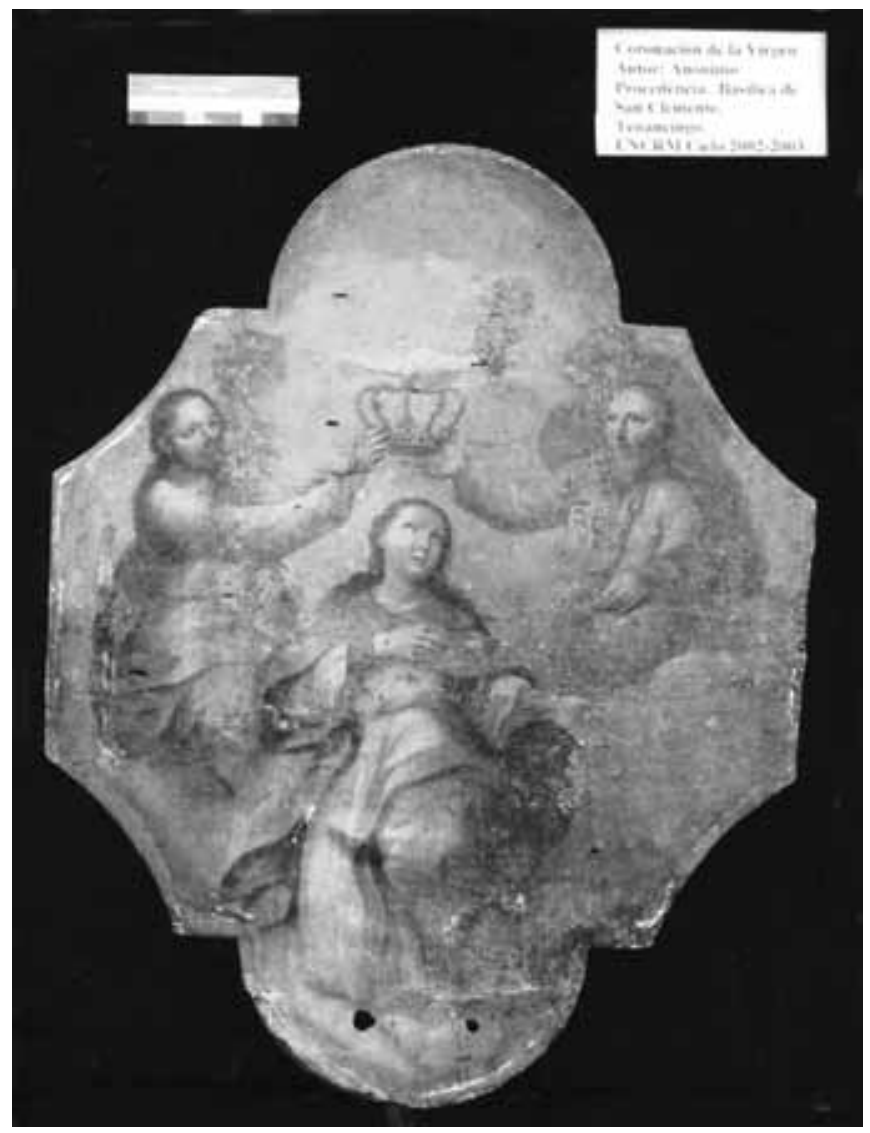

FIGURA 7. Muestra de un lienzo del siglo xIx con baja densidad de tejido y de proveniencia doméstica. La Coronación de la Virgen, colección de la Basílica de San Clemente, Tenancingo, Estado de México (tomado de Botello Brigas 2003; cortesía: Archivo del STRPC-ENCRYM).

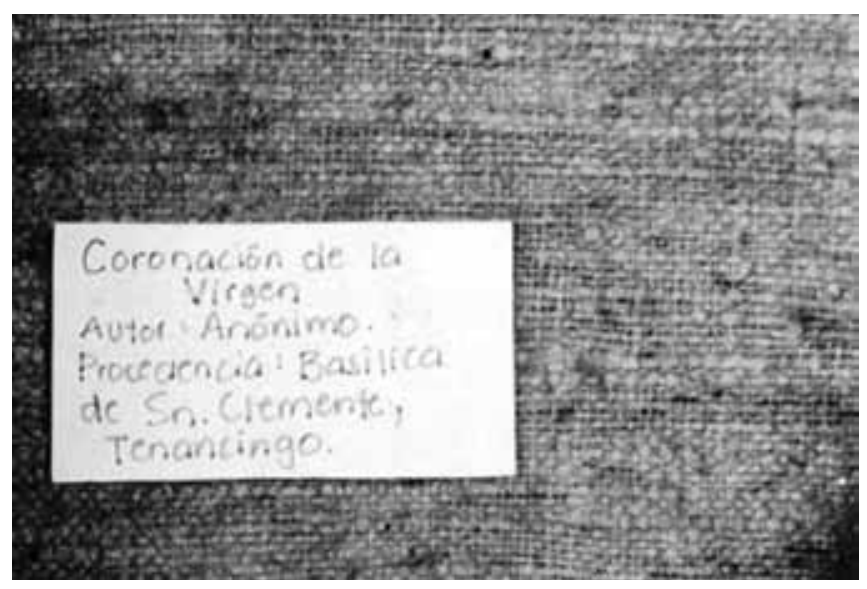

FIGURA 8. Detalle de los nudos en el tejido del cuadro La Coronación de la Virgen, siglo xix. (Tomado de Botello Brigas 2003; cortesía: Archivo del STRPC-ENCRYM). 


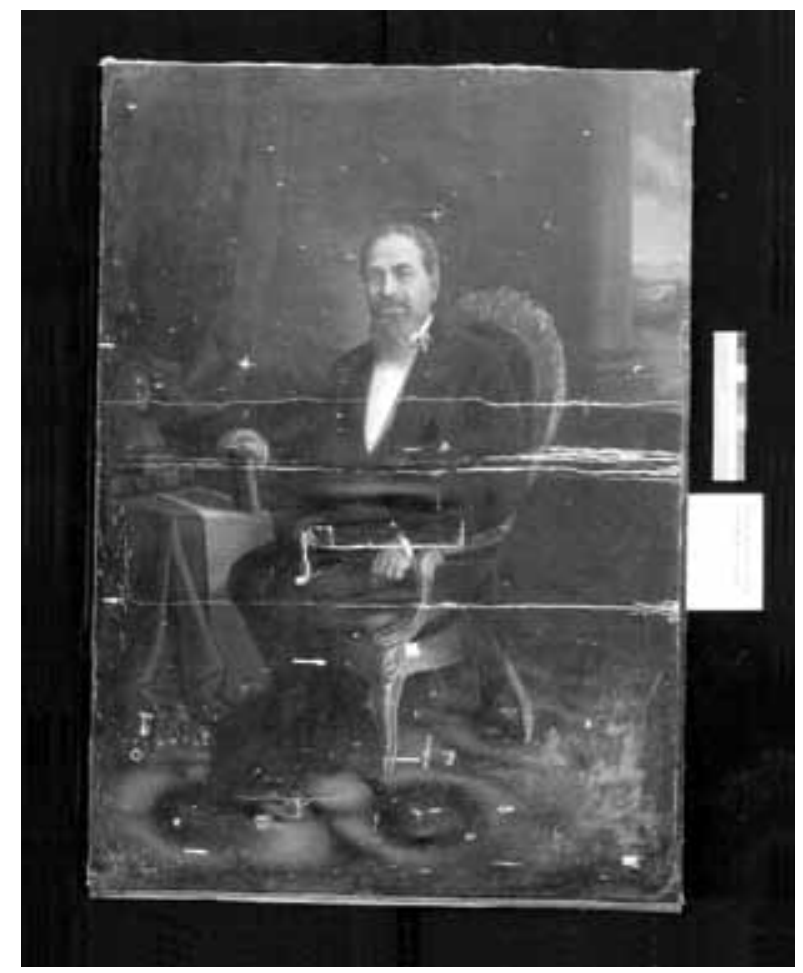

FIGURA 9. Muestra un lienzo del siglo xix con alta densidad de tejido y seguramente proveniente de algún país industrializado. Retrato del general Trinidad García de la Cadena, colección del Museo Regional de Guadalupe, Zacatecas. (Tomado de Meneses Lozano 2004; cortesía: Archivo del STRPC-ENCRYM).

\section{Hilos más gruesos en un sentido}

En el tisaje existen dos disposiciones de la urdimbre: vertical y horizontal. Primero se tira la urdimbre logrando hilos intercalados que están sujetos en los extremos y nunca cambian de posición. Luego se va "rellenando" el tejido con hilos de trama, que se hacen pasar de un lado a otro de las urdimbres y se aprietan con un peine. De los lienzos de cuadros del siglo XVII y XVIII, 15\% reportan tener hilos del tejido más gruesos en un sentido que en otro; aunque son pocos los restauradores que reconocen la urdimbre como la de los hilos más delgados. Por lógica, los hilos gruesos constituyen la trama, pues "rellenan" con más facilidad el tejido, acelerando la factura y aumentando así las ganancias. Esta característica se reduce en el siglo xIx a $2.7 \%$ del total de los lienzos restaurados, lo que es también evidencia de una creciente industrialización en los procesos de factura de los lienzos. Esta particularidad incide también en la conservación de la obra, pues a menudo las urdimbres se rompen primero que la trama, provocando un efecto de deterioro característico, similar al que sucede con algunos tapices (Figura 11).

\section{Dimensiones máximas}

La presencia de orillos (bordes) en varios soportes permitió a los restauradores que trabajaron estas obras observar

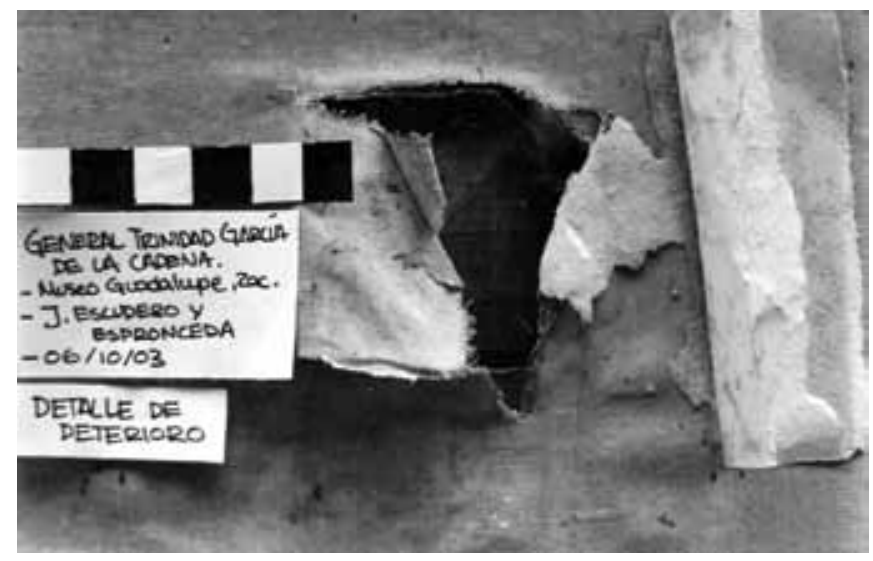

FIGURA 10. Detalle del reverso del Retrato del General Trinidad García de la Cadena, siglo xIx, que muestra la densidad de tejido alta. (Tomado de Meneses Lozano 2004; cortesía: Archivo del STRPC-ENCRyM).

los límites máximos de las telas. De acuerdo con el banco de datos, de los lienzos correspondientes a los siglos XVII y XVIII su anchura no superó los $113 \mathrm{~cm}$; las únicas excepciones que se encontraron fueron dos cuadros: uno de Juan Correa, San Francisco Xavier bautizando, procedente de la misión de Santa María de Cuevas, Chihuahua, que está constituido de tres lienzos de $145 \mathrm{~cm}$ de ancho, unidos con hilo de agave, y uno anónimo, del seminario Arquidiocesano de Chihuahua, Virgen con niño, que consta de cuatro lienzos, uno de ellos de $147 \times 160 \mathrm{~cm}$. Del siglo xIx, 84\% de las pinturas constan de un solo lienzo y no se documenta la presencia de orillos, ya sea porque no los hubo o porque no fueron registrados en los informes.

\section{Conclusiones}

Los datos obtenidos del análisis de los soportes textiles de la pintura de caballete constituyen una fuente de información para la restauración, la historia del arte, la historia social y otras disciplinas afines, ya que en los textiles es posible apreciar un testimonio de la sociedad

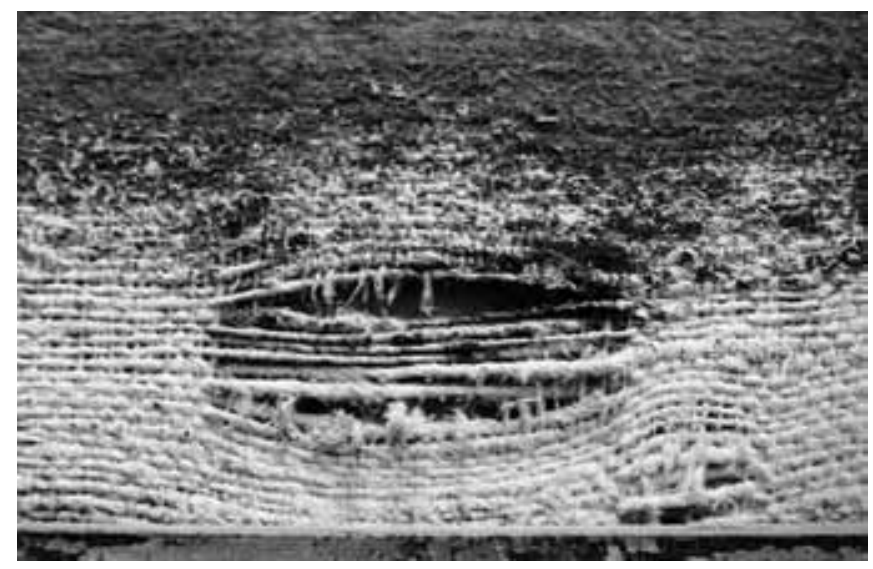

FIGURA 11. Detalle de la rotura de los hilos de la urdimbre. La muerte de Santa Mónica, siglo xvIII. (Tomado de Garay Fernández de Villegas 2007; cortesía: Archivo del STRPC-ENCRYM). 
que los creó, de sus recursos, personalidad y tecnología disponible.

El lino fue la fibra textil más usada para conformar los soportes textiles de las pinturas de caballete de los siglos XVII al XIx en México. Es destacable que el acceso al lino fue, tanto en España como en México, muy limitado, lo que propició una circunstancia particular entre los pintores y productores mexicanos, que hicieron grandes esfuerzos por obtener tafetanes de esta fibra durante cientos de años.

Los soportes de la muestra estudiada que corresponden al siglo xVII son principalmente tafetanes de lino con densidades de tejido de $11 \times 12$ hilos $/ \mathrm{cm}^{2}$, con lienzos de anchos no mayores a los $113 \mathrm{~cm}$. Los del siglo XVIII son también tafetanes de lino con densidad de tejido de $12 x$ $13 \mathrm{hilos} / \mathrm{cm}^{2}$. Pueden estar compuestos por varios lienzos y/o partes de ellos. Los soportes de los siglos xVII y xVIII comparten características, como tener un ancho de lienzo similar; nudos en el tejido en un porcentaje menor de las telas, e hilos más gruesos en el sentido de la trama que el de la urdimbre. Tanto en el siglo xvII como en el XVIII, se utilizaron fibras locales en los hilos de unión de los lienzos, evidencia de la participación de los conocimientos y tecnología indígenas en una actividad introducida por los españoles.

En su mayoría, los soportes textiles del siglo xix que se analizaron resultaron también tafetanes de lino, pero en este siglo se incorporan nuevos ligamentos textiles y nuevas fibras como el yute o el algodón. El ámbito tecnológico del que fueron obtenidos estos lienzos se puede dividir en dos grandes campos: el contexto doméstico y las importaciones de países industrializados. Los primeros lienzos muestran hilado manual, nudos y baja densidad de tejido, mientras que los segundos presentan una alta densidad de tejido (la media, de $17 \times 18$ hilos $/ \mathrm{cm}^{2}$ ), hilos regulares, tejidos cerrados, delgados y homogéneos.

Una gran cantidad de correlaciones pueden hacerse aún con los datos de este estudio, y este modelo podría aplicarse a otros bienes culturales y otros periodos de la historia, por ejemplo, al estudio de las pinturas sobre tabla del siglo XVI, para entender cómo se transformó la preferencia por los soportes textiles, o en las obras del siglo xx, donde se puede hacer una evaluación de la continuidad en la materialidad de las pinturas respecto de los siglos anteriores. Asimismo, es necesario profundizar en la historia particular de las importaciones de los lienzos de lino en México, así como en la implantación de los cultivos de esta y otras fibras textiles, como el yute y la seda.

Con la metodología presentada en esta investigación se ha logrado demostrar que los registros en los informes de trabajo realizados por los restauradores son una fuente de información útil que, organizada e interpretada debidamente, arroja resultados relevantes tanto de las obras como de los aspectos de la producción y el consumo de materiales. Se ha hecho también evidente el particular y privilegiado ejercicio de investigación que realizan los restauradores en su campo, generando conocimiento útil tanto para la profesión como para otras disciplinas afines. Con esta investigación también se ha logrado confirmar o rectificar información importante sobre los soportes textiles de la pintura de caballete en México.

\section{Referencias}

Alcántara Bravo, Charlene Joyce 2008 "Informe del proceso de restauración realizado en Frontal de Altar, perteneciente a la capilla de Santa Lucía en Jonacatepec, Morelos", informe de trabajo inédito, México, STRPC-ENCRYM-INAH.

Barrio Lorenzot, Francisco del (comp.)

1932 Ordenanzas de gremios de la Nueva España, México, Secretaría de Gobernación-Dirección de Talleres Gráficos.

Bringas Botello, Jennifer Libertad

2003 "Informe de los trabajos realizados en la obra La Coronación de la Virgen", informe de trabajo inédito, México, STRPC-ENCRYM-INAH.

Cardona Ramos, Diana

2002 "Informe de los trabajos realizados en la obra Virgen con niño", informe de trabajo inédito, México, STRPC-ENCRYM-INAH.

Casares, Julio 1994 Diccionario ideológico de la lengua española, Madrid, Real Academia de la Lengua Española/ Gustavo Gili.

Diccionario de autoridades, 1964, Real Academia Española, Madrid, Gredos.

Garay Fernández de Villegas, Maia

2007 "Informe de los trabajos realizados en la obra La Muerte de Santa Mónica, Museo de Arte Religioso de Santa Mónica, Puebla", informe de trabajo inédito, México, STRPC-ENCRYM-INAH.

González Angulo, Jorge

1983 Artesanado y ciudad a finales del siglo xVIII, México, FCE.

Johnson Weitlaner, Irmgard

1977 Los textiles de la Cueva de la Candelaria, Coahuila, México, INAH- Departamento de Monumentos Prehispánicos.

Laurenbacher, Konrad 2005 "Reentelados, parches y remiendos. Mucha tela", en Interim meeting: International Conference on painting conservation. Canvases: behavior, deterioration \& treatment, Valencia, Universidad Politécnica de Valencia: 11-119.

López Guzmán, Javier

2008 "Informe de los trabajos realizados a la obra San Andrés, Dolorosa y San Jorge", informe de trabajo inédito, MéXICO, STRPC-ENCRYM-INAH.

Lozano Vega, Paola

1996 "Informe de los trabajos de conservación y restauración de la pintura de caballete San Roque, de la colección del Museo de Tlaxcala", informe de trabajo inédito, México, STRPC-ENCRYM-INAH.

Meneses Lozano, Héctor Manuel

2004 "Informe de los trabajos realizados en la obra Retrato del General Trinidad García de la Cadena", informe de trabajo inédito, México, STRPC-ENCRYM-INAH. 
Miño Grijalva, Manuel

1993 La protoindustria colonial hispanoamericana, México, FCE.

Sánchez, Gloria

1993 "Historia clínica de la obra: Virgen de Guadalupe", informe de trabajo inédito, México, STRPC-ENCRYM-INAH.

Santa Cruz, Alonso de

1951 Crónica de los reyes católicos, tomo II, 1505-1516, Madrid, Escuela de Estudios Hispano-Americanos de Sevilla. Serrera Contreras, Ramón

1974 Cultivo y manufactura de lino y cáñamo en Nueva España (1777-1800), Madrid, Escuela de Estudios HispanoAmericanos de Sevilla/ Consejo Superior de Investigaciones Científicas.

\section{Resumen}

Esta investigación estudia la técnica de factura de los soportes textiles de la pintura de caballete en México de los siglos XVII al XIX. En ella se usan como fuente primaria 200 informes de trabajo sobre pinturas que habían sido restauradas por el Seminario-Taller de Restauración de Pintura de Caballete de la Escuela Nacional de Conservación, Restauración y Museografía entre 1997 y 2009. Los registros sobre técnica de factura de los soportes se organizaron con base en una ficha de análisis textil integrada a una base de datos, para después interpretarlos utilizando estadística descriptiva. Los resultados del análisis estadístico orientaron la investigación histórica, que se sirvió de fuentes vivas, materiales, bibliográficas y documentales.

De esta investigación se desprendieron datos relevantes sobre los soportes textiles en pintura de caballete. El uso de los informes de restauración como fuente de información demuestra la relevancia de esta disciplina y la importancia de practicar un adecuado registro de las intervenciones.

\section{Palabras clave}

Factura, soporte textil, caballete.
Sumano González, Rita 2010 "Estudio de la técnica de factura de los soportes textiles de la pintura de caballete en México, siglos XVII al XIX", tesis de licenciatura en Restauración, México, ENCRYM-INAH.

Trujillo Bolio, Mario

1997 Operarios fabriles en el Valle de México (1864-1884). Espacio, protesta y cultura obrera, México, El Colegio de México, Centro de Investigaciones y Estudios Superiores en Antropología Social.

Viqueira, Carmen y José I. Urquiola

1990 Los obrajes en la Nueva España, 1530-1630, México, Conaculta.

\section{Abstract}

This research focuses on the study of canvas used as support on Mexican paintings during the 17th to 19th centuries. The study was carried out using as primary source of information two-hundred reports of restoration work produced between 1997 and 2009 in the Painting Restoration Workshop at the National School of Conservation, Restoration and Museology of Mexico (STRPC, ENCRYM-INAH). The records were organized into a database according to a textile analysis sheet, and then interpreted using descriptive statistics. The statistical results oriented the historical research, which employed material, documentary and current living sources.

This research revealed relevant data regarding the origin, production, materials, and technology of canvas supports, helping towards their characterization and identification. The use of restoration reports as a primary source of information demonstrates the relevance of the discipline and the importance of an adequate record when preserving cultural heritage.

\section{Keywords}

Canvas painting, Manufacture, Textile support. 